\title{
Deubiquitinating Enzyme Inhibitor Alleviates Cyclin A1-mediated Proteasome Inhibitor Tolerance in Mixed-lineage Leukemia
}

Maolin Ge ( $\sim$ mge@whu.edu.cn)

Shanghai Jiao Tong University https://orcid.org/0000-0002-8803-1463

Qiongyu Xu

Shanghai Jiao Tong University School of Medicine

Ting Kang

Shanghai Jiao Tong University School of Medicine

Dan Li

Shanghai Jiao Tong University School of Medicine

Ruiheng Wang

Shanghai Jiao Tong University

Zhihong Chen

Shanghai Jiao Tong University

Shufeng Xie

Shanghai Jiao Tong University

Wenbin Wang

Shanghai Jiao Tong University School of Medicine

Han Liu

Shanghai Jiao Tong University School of Medicine

\section{Research}

Keywords: proteasome inhibitor, drug tolerance, mixed-linage leukemia, cyclin A1, deubiquitinating enzyme inhibitor

Posted Date: December 17th, 2020

DOI: https://doi.org/10.21203/rs.3.rs-125310/v1

License: (c) (i) This work is licensed under a Creative Commons Attribution 4.0 International License.

Read Full License 


\section{Abstract}

Background: Drug resistance is a significant obstacle to effective cancer treatment. Drug resistance develops from initially reversible drug-tolerant cancer cells, which offers therapeutic opportunities to impede cancer relapse. The mechanisms of resistance to proteasome inhibitor (PI) therapy have been investigated intensively; however, the ways by which drug-tolerant cancer cells orchestrate their adaptive responses to drug challenges remains largely unknown.

Methods: RNA sequencing and bioinformatics analyses were employed to assess dysregulated cell cycle genes. Chromatin immunoprecipitation assays were performed to evaluate the involvement of MLL in cyclin A1 transcriptional activity. Cell cycle assays, cell viability assays, immunoblots, and apoptosis assays were performed to evaluate the dependency of cyclin A1 during tolerance acquisition.

Results: Here, we demonstrated that cyclin A1 suppression elicited the development of transient PI tolerance in mixed-lineage leukemia (MLL) cells. This adaptive process involved reversible downregulation of cyclin A1, which promoted PI resistance through cell cycle arrest. Pl-tolerant MLL cells acquired cyclin A1 dependency, regulated directly by MLL protein. Loss of cyclin A1 function resulted in the emergence of drug tolerance, which was associated with patient relapse and reduced survival. Combination treatment with $\mathrm{PI}$ and deubiquitinating enzyme (DUB) inhibitors overcame this drug resistance by restoring cyclin $\mathrm{A} 1$ expression through chromatin crosstalk between histone $\mathrm{H} 2 \mathrm{~B}$ monoubiquitination and MLL-mediated histone H3 lysine 4 methylation.

Conclusion: These results reveal the importance of cyclin A1-engaged cell cycle regulation in PI resistance in MLL cells, and suggest that cell cycle re-entry by DUB inhibitors may represent a promising epigenetic therapeutic strategy to prevent acquired drug resistance.

\section{Background}

Cancer cells are highly plastic to the cytotoxic stress response during the development of drug resistance. ${ }^{1,2}$ During rapid exposure to lethal chemotherapies, drug-sensitive cancer cells initially undergo apoptosis, leading to significant cell death and tumor regression. However, the remaining drug-tolerant cancer cells may follow different evolutionary paths and eventually acquire resistance. ${ }^{3-5}$ Although drug resistance is widely considered to be genetically determined, emerging evidence has indicated a key role for non-mutational mechanisms in the survival of drug-tolerant cells. ${ }^{6,7}$ These cells are thought to be capable of surviving strong apoptotic stimulation until more permanent long-term resistance mechanisms are developed. ${ }^{8}$ This transient drug-tolerant state is usually achieved by slowing down essential cellular processes, and is thought to be the initial mechanism in the eventual acquisition of long-term resistance. ${ }^{3,5,9}$ Targeting drug-tolerant cancer cells and reversing their tolerance therefore provide a promising therapeutic opportunity to impede tumor relapse. $5,10,11$ 
Proteasome inhibitors (PIs) have dramatically improved the treatment of multiple myeloma (MM) and other hematological malignancies, but relapses are frequent and acquired resistance to treatment eventually emerges. ${ }^{12,13}$ Mixed-lineage leukemia (MLL), including acute lymphoblastic leukemia (ALL) and acute myeloid leukemia (AML), is an aggressive hematologic malignancy with a poor prognosis. ${ }^{14}$ Chromosome 11q23 translocations involving the $M L L$ gene (also known as KMT2A) predominantly occur in pediatric patients, accounting for $\sim 80 \%$ of infant leukemias and $\sim 10 \%$ of adult acute leukemias. ${ }^{15-17}$ We previously reported that the PI bortezomib was effective in mouse models and in patients with pro-B MLL leukemia. ${ }^{18}$ However, the inevitable emergence of PI resistance limits the clinical application of bortezomib. 19, 20 There is thus a need to identify the mechanism underlying PI resistance and to design novel combination strategies to overcome resistance and promote the application of PIs for MLL leukemias.

Drug tolerance is induced by therapeutic stresses through a reversible reprogramming of the cell cycle, leading to a dormant or quiescent state, in which cancer cells survive but do not proliferate. ${ }^{8}$ The histone methyltransferase MLL orchestrates several essential cellular processes by positively regulating the Hox and cell cycle genes. ${ }^{21,22}$ Upon PI treatment, MLL leukemic cells initially enter a slow-cycling, stemnessenhanced, and reversible drug-tolerant state. ${ }^{20}$ The remaining drug-tolerant cells eventually acquire resistance through PI-induced epigenetic reprogramming and subsequent loss of MLL protein function and cell cycle deregulation. ${ }^{19}$ However, little is known about how MLL cells orchestrate their cell cycle adaptive response under PI challenge.

Deregulation of the cell cycle machinery is a common feature of cancer cells, and dysregulation of cell cycle control, particularly in the G1/S phase, is thought to contribute to the development of solid tumors and hematological malignancies. Cyclins are well-established regulators of the cell cycle, with indispensable roles in processes such as transcription, epigenetic regulation, tumorigenesis, and resistance to checkpoint blockade. ${ }^{23}$ Cyclin $\mathrm{A} 1$ is predominantly expressed in normal testis and is highly expressed in leukemic and hematopoietic cells. ${ }^{24,25}$ Cyclin A1 positively regulates the G1/S and S/G2 phase transitions. ${ }^{26}$ Elevated levels of cyclin A1 in AML cells are associated with increased survival. ${ }^{27}$ Some agents can abrogate the cell cycle checkpoints to make cancer cells susceptible to apoptosis, ${ }^{28}$ while the induction of cell cycle entry can improve the efficiency of anti-proliferative drugs and eliminate leukemia stem cells. ${ }^{29}$ However, our mechanistic understanding of whether modulating cyclin A1 contributes to the progression of leukemic resistance is negligible.

In the current study, we show that cyclin A1 mediated the development of PI tolerance in MLL cells and resulted in patient relapse. PI treatment induces remodeling of histone $\mathrm{H} 2 \mathrm{~B}$ monoubiquitination (H2Bub). ${ }^{19,30}$ H2Bub depletion could impair the recruitment of MLL to chromatin and H3K4 methylation. ${ }^{31-33}$ The crosstalk between H2Bub and MLL-mediated H3K4 methylation also affects the expression of cell cycle genes. Thus, we postulated that the altered chromatin state caused by the deubiquitinating enzyme (DUB) inhibitors in tolerant cells might overcome bortezomib resistance in tolerant cells. 


\section{Methods}

Reagents. Bortezomib (Velcade), P5091 (P005091), Degrasyn (WP1130), and etoposide were obtained from Selleck Chemicals.

Cell culture and generation of drug-tolerant cells. Human pro-B MLL leukemia cell lines RS4;11 and SEM $^{34}$ were purchased from DSMZ. Cells were cultured in Gibco RPMI- 1640 containing $10 \% \mathrm{FBS}$ at $37^{\circ} \mathrm{C}$ with $5 \% \mathrm{CO}_{2}$ and were maintained between a density of $5 \times 10^{5} \mathrm{cells} / \mathrm{ml}$ and $2 \times 10^{6} \mathrm{cells} / \mathrm{ml}$. The generation of induced drug-tolerant cells has been described previously. ${ }^{20}$ Briefly, naive cells were exposed to a sublethal dose of bortezomib $(5 \mathrm{nM})$ for 2 weeks, replenishing the inhibitor every 3 days. The remaining cells after the treatment were considered as 'Tolerant' cells and were collected for analysis. 'Reverted' cells were generated from bortezomib-tolerant cells by culturing without bortezomib for a minimum of 4 weeks. All cultured cells were tested for mycoplasma contamination before use.

Cell viability and cell proliferation assays. The CellTiter 96 MTS-assay (Promega) was used to determine the cytotoxicity of the relevant drugs and cell proliferation, according to the manufacturer's instructions. Cell viability was measured with MTS assay $24 \mathrm{hr}$ after the addition of drug with graded concentrations in triplicates.

Apoptosis and cell cycle assays. Apoptosis and cell cycle were measured using the PE Annexin V Apoptosis Detection Kit and APC BrdU Flow Kit from BD Pharmingen as described by the manufacturer, respectively. The percentages of different cell cycle phases (G1, S, and G2/M) were quantified. Cells staining with fluorochromes were acquired using flow cytometer and data was analyzed using FlowJo software.

shRNA-mediated knockdown and qRT-PCR. Target sequences (CTCCTGAAGTAGACGAGTTTG\#1 and CACAAGAATCAGGTGTTATTC\#2) against human cyclin A1, target sequences (GCCAAGCACTGTCGAAATTAC\#1 and TCTACCAACCCTAAACCCTGA\#2) against human MLL C-terminus, and a control scrambled sequence (GCGCGCTTTGTAGGATTCGTT) that has no significant homology with the human genome were inserted into the pLKO.1 vector, according to the manufacturer's protocol (Addgene). Generated lentivirus carrying shRNA was used to infect target cells for 2 days, and the cells were subjected to puromycin selection at $2 \mu \mathrm{g} / \mathrm{ml} .{ }^{35}$ Cellular RNA samples were reverse transcribed with random primers and detection was performed using 7500 Real-Time PCR Systems (Applied Biosystems). The data represent absolute mRNA copy numbers normalized to GAPDH used as a reference gene. ${ }^{36}$ Relative fold expression values were determined by applying the ${ }^{\triangle \triangle} \mathrm{Ct}$ method. Primers used for qRT-PCR assay were CCNA1: forward, AGTGGAGTTGTGCTGGCTAC, reverse, GTCAGGGAGTGCTTTCTTTC; KMT2A (MLL): forward, ACAGAAAAAAGTGGCTCCCCG, reverse, GCAAACCACCCTGGGTGTTA.

Plasmid constructions. The mutant $C C N A 1$ (CCNA1 mut, ctcctgaagtagacgagtttg to caccagaggttgatgaattcg) was inserted into the PCDH-MCS-T2A-copGFP-MSCV vector, according to the manufacturer's protocol (System Biosciences). The CCNA1mut plasmid was constructed based on the 
shCCNA1-1 sequence, which changed the base sequence without changing the amino acids, so that it would not be affected by the shRNA. Generated lentivirus carrying CCNA1mut was used to infect target cells.

Immunoblots. Human CD133-PE was obtained from Miltenyi Biotec. Mouse antibody against cyclin A1 was obtained from BD Biosciences. Rabbit antibodies against MLL ${ }^{\mathrm{C} 180}$ (D6G8N), Ubiquityl-Histone H2B (Lys120) (H2Bub), Tri-Methyl-Histone H3 (Lys4) (H3K4me3), Phospho-Histone H2A.X (Ser139) (y-H2AX), Histone $\mathrm{H} 3$, and mouse anti-Histone $\mathrm{H} 2 \mathrm{~B}$ antibody were purchased from Cell Signaling Technology. Mouse anti- $\beta$-Actin antibody was obtained from Sigma Aldrich. Antibodies were detected using the enhanced chemiluminescence method (Western Lightning, PerkinElmer). Immunoblot signals were acquired with the Amersham Imager 600 (General Electric Company).

Total RNA sequencing (RNA-Seq). Total RNA was extracted from Trizol according to the manufacturer's instructions. The mRNA-seq library was performed by using Illumina TruSeq library construction kit. A 2 $\mu \mathrm{g}$ of total RNA was used as initiation and then prepared according to the manufacturer's instruction. The mRNA-seq libraries were sequenced using BGISEQ-500 for 100-bp paired-end sequencing. Quality control of mRNA-seq data was performed using Fatsqc, and then low-quality bases were trimmed. After quality control, clean reads were aligned to the human genome (UCSC hg19) by Tophat2.1.0 with maximum of 2 mismatches for each reads. After data mapping cufflinks were used to analyze significant differential expression genes. Gene set enrichment analysis (GSEA) was executed using public software from the Broad Institute (http://software.broadinstitute.org/gsea).

Chromatin immunoprecipitation (ChIP) assays. ChIP assays were performed following the described protocol ${ }^{37}$ using anti-MLL ${ }^{\mathrm{C} 180}$ and $\mathrm{H} 3 \mathrm{~K} 4 \mathrm{me} 3$ antibodies. Precipitated DNA was sequenced or analyzed using the 7500 Real-Time PCR Systems. ${ }^{38}$ Primers used for ChIP-PCR assay were located at the CCNA1 promoter region (-503 base pairs [bp] to -348 bp relative to transcription start site [TSS]): forward, AAGCGTAGGTGTGTGAGCCGA, reverse, AACAACCCCCTCTAACGTCTC.

Statistical analysis. The Student's $t$-test or log-rank test were used to analyze the differences between the groups. Means were illustrated using a histogram with error bars representing \pm the standard deviation (SD), and statistical relevance was evaluated using the following $P$ values: $P<0.05\left({ }^{*}\right), P<0.01$ (**), or $P$ $<0.001(* \star *)$.

\section{Results}

\section{Cyclin A1 is downregulated in drug-tolerant MLL cells}

We previously observed that pro-B MLL leukemia displayed selective sensitivity to the PI bortezomib, but reversible resistance inevitably emerged. ${ }^{18,20}$ Cancer cells primarily acquire a drug-tolerant state under therapy stress, often by slowing down essential cellular processes. ${ }^{5}$ Similar to other drug-tolerance mechanisms, ${ }^{5,11}$ the emergence of PI tolerance is accompanied by cell cycle arrest and growth 
inhibition. ${ }^{20,39}$. We determined the reversible features of slow-cycling PI tolerance in bortezomib-tolerant SEM and RS4;11 cells by continuously treating the parental cells with sublethal doses of bortezomib for 2 weeks, replenishing the inhibitor every 3 days. The cells remaining after the treatment were considered as PI-tolerant cells and were collected for analysis. Reverted cells were generated from bortezomib-tolerant cells by culturing without bortezomib for a minimum of 4 weeks. We further characterized these PItolerant MLL cells by RNA sequencing (RNA-Seq). We created replicates of PI-tolerant and reverted cells to reduce the differences between samples. Hierarchical clustering of differentially expressed genes (DEGs) revealed distinct clusters of gene expression patterns (Fig. 1a). Compared with PI-tolerant cells, reverted and parental cells showed similar gene expression patterns, indicating the reversibility of PI tolerance. We also performed gene set enrichment analysis (GSEA) using datasets obtained from tolerant and reverted cells, and observed an enrichment of genes involved in the cell cycle (Fig. 1b, c). Notably, the CCNA1 gene (encoding cyclin A1) was remarkably downregulated in PI-tolerant cells (Fig. 1b, c). Moreover, levels of CCNA1 mRNA and cyclin A1 protein were significantly decreased in PI-tolerant MLL cells but recovered in the reverted cells (Fig. 1d, e). These results indicate that slow-cycling PI-tolerant MLL cells are associated with reduced CCNA1 expression.

\section{Cyclin A1 suppression induces drug tolerance in MLL cells}

Cyclin A1 is an essential component of the cell-cycle engine that positively regulates G1/S and S/G2 phase transitions, ${ }^{26}$ and we therefore investigated if cyclin $\mathrm{A} 1$ played a specific role in PI tolerance. Lentiviruses carrying short hairpin RNA (shRNA) targeting cyclin A1 (shCCNA1-1 and shCCNA1-2) were constructed and used to infect SEM cells (Fig. 2a). CCNA1 knockdown decreased the percentages of $S$ and G2/M phase cells (Fig. 2b) and suppressed the proliferation of infected SEM cells (Fig. 2c), suggesting that CCNA1 knockdown induced slow-cycling cells. We conducted cell viability assays and showed that CCNA1 knockdown significantly reduced the sensitivity of SEM cells to bortezomib (Fig. 2d). We further constructed a mutant CCNA1 plasmid (CCNA1 mut) for shCCNA1-1, in which the base sequence was changed but the amino acid sequence remained the same, which was therefore not affected by the shRNA (Fig. 2e). The tolerance induced by shCCNA1 in SEM cells was notably rescued by the introduction of CCNA1mut (Fig. 2f). Taken together, these results indicate that downregulation of CCNA1 plays a causal role in the development of PI tolerance in MLL cells.

\section{MLL directly regulates the transcriptional activity of cyclin A1}

The CCNA1 gene is transcriptionally regulated by E2F1, MYB, and pRB (RBL1 and RBL2). ${ }^{26,40}$ To examine the mechanism of $C C N A 1$ reduction, we therefore evaluated the expression levels of these CCNA1 regulators. mRNA levels of these regulators were not significantly reduced in PI-tolerant SEM and RS4;11 cells (Fig. 3a), suggesting that factors other than these were responsible for suppressing CCNA1 expression in PI-tolerant cells.

CCNA1 repression in quiescent cells is associated with chromatin modification of its promoter. ${ }^{41}$ Moreover, the reversibility of $\mathrm{PI}$ tolerance is indicative of an epigenetic rather than a genetic mechanism, ${ }^{3}$, 
42 and transcription of the CCNA1 gene can be regulated by MLL-mediated histone H3 lysine 4 trimethylation ( $\mathrm{H} 3 \mathrm{~K} 4 \mathrm{me} 3)$ on its promoter. ${ }^{21,22,41}$ We therefore examined if the tolerant state was associated with changes in MLL and H3K4me3 modification of the CCNA1 promoter. ${ }^{43}$ To confirm the association between MLL reduction and CCNA1 suppression, we knocked down the $M L L$ gene in SEM cells and observed that MLL depletion significantly reduced CCNA1 gene expression (Fig. $3 \mathbf{b}$ ). We then performed chromatin immunoprecipitation sequencing (ChIP-seq) analysis using MLL-CT antibody $\left(M_{L L}{ }^{C 180}\right)$ in parental, tolerant, and reverted SEM cells. ChIP assays showed that the MLL antibody had decreased CCNA1 promoter occupancy in SEM tolerant cells (Fig. 3c). Moreover, compared with parental and reverted cells, PI-tolerant cells showed a significantly decreased levels of both global and CCNA1 promoter-bound MLL and H3K4me3 (Fig. 3d, e). In addition, consistent with a critical role in the drugresistance and DNA-damage responses, ${ }^{19,} 22,44$ reduction of MLL in Pl-tolerant cells was associated with an increase in histone $\mathrm{y}-\mathrm{H} 2 \mathrm{AX}$ (Fig. 3e). Furthermore, etoposide-induced $\mathrm{y}-\mathrm{H} 2 \mathrm{AX}$ levels were notably increased in Pl-tolerant cells compared with parental and reverted cells (Fig. 3f). These results indicate that PI-tolerant cells are prone to DNA damage, potentially resulting in secondary mutations and hardwired drug resistance, which could partly explain why the reverted cells failed to regain full sensitivity to PI compared with the parental cells. Overall, these results suggest that cyclin A1 is regulated by MLL and mediates PI tolerance in MLL cells.

\section{Prognostic relevance of MLL and cyclin A1 expression in ALL patients}

To clarify the clinical significance of MLL and cyclin A1 expression, we examined the relationships between KMT2A (encoding MLL) and CCNA1 gene expression levels and patient survival in ALL patients from a pediatric ALL dataset (Phase II, TARGET, 2018). Interestingly, compared with initially treated patients, patients who relapsed following chemotherapy showed significantly reduced expression levels of KMT2A and CCNA1 (Fig. 4a), consistent with our findings in drug-tolerant cells. Furthermore, KaplanMeier analysis with a 50\% cut-off value revealed that ALL patients with low KMT2A and CCNA1 expression levels had significantly lower overall survival compared with those with high expression levels ( $P=0.0003$ and $P=0.0185$, respectively; Fig. 4b). Taken together, these results indicate that KMT2A and CCNA1 expression may have prognostic relevance in terms of patient survival and chemotherapy relapse, with downregulation of MLL and cyclin A1 being correlated with shorter survival in patients with ALL.

\section{DUB inhibitors show potential efficacy in PI-tolerant MLL cells}

Pl-induced H2Bub depletion affects MLL function and the expression of cell cycle genes. ${ }^{19}$ We hypothesized that DUB inhibitors could overcome bortezomib resistance in tolerant cells by promoting the elevation of H2Bub. Furthermore, the DUB inhibitors P5091 and WP1130 are currently being tested in combination with various anticancer therapies. ${ }^{45,46}$ Notably, H2Bub and H3K4me3 were significantly induced by P5091 and WP1130, leading to increased cyclin A1 expression (Fig. 5a). Consistently, CCNA1 mRNA was significantly induced by DUB inhibitors in PI-tolerant cells (Fig. 5b). ChIP assays demonstrated that MLL and H3K4me3 had increased CCNA1 promoter occupancy in SEM tolerant cells (Fig. 5c). Interestingly, although MLL was not significantly upregulated by DUB inhibitors in PI-tolerant 
cells (Fig. 5a), ChIP assays revealed incremental loading of MLL following DUB inhibitor treatment (Fig. 5c), indicating that DUB inhibitors induce $\mathrm{H} 2 \mathrm{Bub}$ and $\mathrm{H} 2 \mathrm{Bub}$-dependent $\mathrm{H} 3 \mathrm{~K} 4 \mathrm{me} 3$ modification via crosstalk between H2Bub and MLL-mediated H3K4 methylation, promoting CCNA1 expression and potentially restoring cell sensitivity. Co-treatment of bortezomib with P5091 or WP1130 led to a strong reduction in cell viability (Fig. 5d, e) and induced notable apoptosis in Pl-tolerant cells (Fig. 5f, g). Collectively, these findings suggest that a dual strategy using PIs and DUB inhibitors might be effective in preventing PI tolerance.

\section{Discussion}

Drug tolerance is induced by therapeutic stresses through reversible reprogramming of the cell cycle, leading to a dormant or quiescent state, in which cancer cells survive but do not proliferate. ${ }^{8}$ These drugtolerant cells subsequently accumulate gene mutations or epigenetic changes that facilitate the emergence of drug resistance, associated with cell cycle exit and concomitant unresponsiveness to applied therapies. ${ }^{47}$ The acquired cell-cycle defects in tolerance cells are associated with specific vulnerabilities that distinguish them from their normal counterparts and provide a window of opportunity for therapeutic strategies. ${ }^{28}$ Here, we demonstrated that cyclin A1 was significantly reduced in PI-tolerant MLL cells, and that restoring cyclin A1 was effective in overcoming PI tolerance. These results highlight the importance of preventing the emergence of drug-tolerant cancer cells in cancer therapy. Conceivably, attenuating the acquisition of drug tolerance by modulating deregulation of the cell cycle process might be an effective means of preventing treatment failure and relapse.

Cyclins are generally implicated as oncogenes when cancer cells undergo cell cycle deregulation, and some cyclin-dependent kinase inhibitors are thought to act as cancer suppressors in a variety of malignancies. ${ }^{48,49}$ From the treatment perspective, drug-tolerance-mediated resistance provides an operational framework for developing therapeutic strategies. ${ }^{47}$ One approach, known as a "sleeping strategy", aims to keep cancer cells dormant, ${ }^{50}$ while the "awakening strategy" stimulates cancer cells to re-enter the cell cycle to improve anti-tumor efficiency. ${ }^{29}$ The third method involves the induction of senescence in quiescent cells by inhibiting autophagy. ${ }^{51}$ Some agents target quiescent cells through these approaches to make cancer cells susceptible to apoptosis. ${ }^{28,29}$ The current study demonstrated that cell cycle deregulation mediated by cyclin $\mathrm{A} 1$ suppression elicited the development of transient PI tolerance, while DUB inhibitors increased H2Bub-dependent H3K4 methylation and induced cyclin A1 expression. These findings revealed that induction of cell cycle entry could improve the efficiency of eliminating drug-tolerant cells and overcoming PI tolerance, indicating that re-entry into the cell cycle may represent a therapeutic strategy to prevent acquired drug resistance.

Many mechanisms have been proposed for PI resistance, especially in MM cells. MM cells are known to have increased demands for protein synthesis and are therefore more susceptible to the cytotoxic effects of proteasome inhibition, which disrupts protein homeostasis. ${ }^{52,53}$ Recent findings have consistently highlighted the importance of re-establishing protein homeostasis to overcome PI resistance. ${ }^{12,13,53,54}$ 
However, unlike myeloma cells, pro-B MLL leukemic cells have low levels of protein synthesis, suggesting that MLL leukemic cells might achieve PI resistance via different strategies. PI treatment induces MLL leukemic cells to acquire a reversible drug-tolerant state, which represents the initial mechanism leading to eventual drug resistance. ${ }^{20}$ The current results demonstrate that the development of PI tolerance is dependent on cyclin A1, which is regulated directly by MLL protein. Moreover, reduction in MLL and cyclin A1 results in drug resistance and relapse, leading to reduced survival. The clinical significance of cyclin A1 expression in different leukemia types has previously been evaluated. ${ }^{27,55}$ The present results indicate that MLL and cyclin A1 expression might have notable prognostic relevance in terms of patient survival and chemotherapy relapse, and that downregulation of MLL and cyclin A1 is correlated with short survival in ALL patients.

Our finding that PI-tolerant MLL leukemic cells were prone to DNA damage reinforced the idea that mutational and non-mutational mechanisms underlying drug resistance are not necessarily mutually exclusive. ${ }^{8}$ Transient effects such as tolerance and persistence have been suggested to provide initial resistance, while the addition of drugs then induces epigenetic reprogramming until secondary mutations convert the progression to relapse, and the cells become genetically hardwired. ${ }^{5,56,57}$ The present study further suggested that this 'rewiring' involving epigenetic chromatin modifications are not only conferred initial fitness, but also facilitated the hardwiring process giving rise to inheritable resistance.

\section{Conclusion}

In conclusion, we clarified the relationship between MLL and cyclin A1 expression and the generation of drug-tolerant cells (Fig. $5 \mathrm{~h}$ ). The reversible and DNA-damage-prone tolerant state is associated with cyclin A1 dysfunction, which in turn promotes the eventual acquisition of $\mathrm{PI}$ resistance. The results also suggested that combination therapy with PIs and DUB inhibitors may be more effective in treating MLL leukemias than solo therapy, by preventing the emergence of tolerant cells. The use of DUB inhibitors to restore cyclin A1 expression also suggests that cell cycle re-entry may be a therapeutic target for preventing acquired drug resistance, which may also extend to cancers other than MLL leukemia.

\section{Abbreviations}

Pl: proteasome inhibitor

MLL: mixed-lineage leukemia

DUB: deubiquitinating enzyme

MM: multiple myeloma

ALL: acute lymphoblastic leukemia

H2Bub: histone H2B monoubiquitination 
ChIP-seq: Chromatin immunoprecipitation sequencing

GSEA: Gene set enrichment analysis

\section{Declarations}

\section{Availability of data and materials}

All data generated or analyzed during the current study are included in this published article. Further information is available from the corresponding author upon reasonable request.

\section{Acknowledgements}

Not applicable.

\section{Funding}

This work was supported by the National Natural Science Foundation of China (81973996 and 81570119), the Shanghai Municipal Education Commission Gaofeng Clinical Medicine Grant (20161304), the Program of Shanghai Academic/Technology Research Leader (19XD1402500), the Shanghai Municipal Health Commission (2019CXJQ01), and the Collaborative Innovation Center of Hematology.

\section{Authors' Contributions}

MG designed and performed most of the experiments, analyzed the data, and wrote the draft manuscript; QX performed some experiments; TK, DL, RW, ZC, SX and WW performed some experiments and analyzed the data; $\mathrm{HL}$ contributed grant support, designed the entire project, and wrote the manuscript. All authors discussed the results and commented on the manuscript.

\section{Ethics approval and consent to participate}

Not applicable.

\section{Consent for publication}

Not applicable.

\section{Competing interests}

The authors declare that they have no competing interests.

\section{References}


1. Brown R, Curry E, Magnani L, Wilhelm-Benartzi CS, Borley J. Poised epigenetic states and acquired drug resistance in cancer. Nature reviews Cancer 2014 Nov; 14(11): 747-753.

2. Kartal-Yandim M, Adan-Gokbulut A, Baran Y. Molecular mechanisms of drug resistance and its reversal in cancer. Critical reviews in biotechnology 2016 Aug; 36(4): 716-726.

3. Shaffer SM, Dunagin MC, Torborg SR, Torre EA, Emert B, Krepler C, et al. Rare cell variability and druginduced reprogramming as a mode of cancer drug resistance. Nature 2017 Jun 15; 546(7658): 431435 .

4. Kim C, Gao R, Sei E, Brandt R, Hartman J, Hatschek T, et al. Chemoresistance Evolution in TripleNegative Breast Cancer Delineated by Single-Cell Sequencing. Cell 2018 May 3; 173(4): 879-893 e813.

5. Sharma SV, Lee DY, Li B, Quinlan MP, Takahashi F, Maheswaran S, et al. A chromatin-mediated reversible drug-tolerant state in cancer cell subpopulations. Cell 2010 Apr 2; 141(1): 69-80.

6. Brauner A, Fridman O, Gefen O, Balaban NQ. Distinguishing between resistance, tolerance and persistence to antibiotic treatment. Nature reviews Microbiology 2016 Apr; 14(5): 320-330.

7. Glickman MS, Sawyers CL. Converting cancer therapies into cures: lessons from infectious diseases. Cell 2012 Mar 16; 148(6): 1089-1098.

8. Salgia R, Kulkarni P. The Genetic/Non-genetic Duality of Drug 'Resistance' in Cancer. Trends in cancer 2018 Feb; 4(2): 110-118.

9. Lee MC, Lopez-Diaz FJ, Khan SY, Tariq MA, Dayn Y, Vaske CJ, et al. Single-cell analyses of transcriptional heterogeneity during drug tolerance transition in cancer cells by RNA sequencing. Proceedings of the National Academy of Sciences of the United States of America 2014 Nov 4; 111(44): E4726-4735.

10. Knoechel B, Roderick JE, Williamson KE, Zhu J, Lohr JG, Cotton MJ, et al. An epigenetic mechanism of resistance to targeted therapy in T cell acute lymphoblastic leukemia. Nat Genet 2014 Apr; 46(4): 364-370.

11. Wang Y, Zhang J, Ren S, Sun D, Huang HY, Wang H, et al. Branched-Chain Amino Acid Metabolic Reprogramming Orchestrates Drug Resistance to EGFR Tyrosine Kinase Inhibitors. Cell Rep 2019 Jul 9; 28(2): 512-525 e516.

12. Manasanch EE, Orlowski RZ. Proteasome inhibitors in cancer therapy. Nature reviews Clinical oncology 2017 Jul; 14(7): 417-433.

13. Moreau P, Richardson PG, Cavo M, Orlowski RZ, San Miguel JF, Palumbo A, et al. Proteasome inhibitors in multiple myeloma: 10 years later. Blood 2012 Aug 2; 120(5): 947-959.

14. Muntean AG, Hess JL. The pathogenesis of mixed-lineage leukemia. Annual review of pathology 2012; 7: 283-301.

15. Hong SK, Lee H, Kwon OS, Song NY, Lee HJ, Kang S, et al. Large-scale pharmacogenomics based drug discovery for ITGB3 dependent chemoresistance in mesenchymal lung cancer. Molecular cancer 2018 Dec 18; 17(1): 175. 
16. Krivtsov AV, Armstrong SA. MLL translocations, histone modifications and leukaemia stem-cell development. Nat Rev Cancer 2007 Nov; 7(11): 823-833.

17. Meyer C, Burmeister T, Groger D, Tsaur G, Fechina L, Renneville A, et al. The MLL recombinome of acute leukemias in 2017. Leukemia 2018 Feb; 32(2): 273-284.

18. Liu H, Westergard TD, Cashen A, Piwnicaworms DR, Kunkle L, Vij R, et al. Proteasome Inhibitors Evoke Latent Tumor Suppression Programs in Pro-B MLL Leukemias Through MLL-AF4. Cancer Cell 2014; 25(4): 530.

19. Ge M, Li D, Qiao Z, Sun Y, Kang T, Zhu S, et al. Restoring MLL reactivates latent tumor suppressionmediated vulnerability to proteasome inhibitors. Oncogene 2020 Sep; 39(36): 5888-5901.

20. Ge M, Qiao Z, Kong Y, Lu H, Liu H. Exosomes mediate intercellular transfer of non-autonomous tolerance to proteasome inhibitors in mixed-lineage leukemia. Cancer Sci 2020 Apr; 111(4): 12791290.

21. Takeda S, Chen DY, Westergard TD, Fisher JK, Rubens JA, Sasagawa S, et al. Proteolysis of MLL family proteins is essential for taspase1-orchestrated cell cycle progression. Genes Dev 2006 Sep 1; 20(17): 2397-2409.

22. Liu H, Takeda S, Kumar R, Westergard TD, Brown EJ, Pandita TK, et al. Phosphorylation of MLL by ATR is required for execution of mammalian S-phase checkpoint. Nature 2010 Sep 16; 467(7313): 343-346.

23. Lim S, Kaldis P. Cdks, cyclins and CKIs: roles beyond cell cycle regulation. Development 2013 Aug; 140(15): 3079-3093.

24. Ochsenreither S, Majeti R, Schmitt T, Stirewalt D, Keilholz U, Loeb KR, et al. Cyclin-A1 represents a new immunogenic targetable antigen expressed in acute myeloid leukemia stem cells with characteristics of a cancer-testis antigen. Blood 2012 Jun 7; 119(23): 5492-5501.

25. Yang R, Nakamaki T, Lubbert M, Said J, Sakashita A, Freyaldenhoven BS, et al. Cyclin A1 expression in leukemia and normal hematopoietic cells. Blood 1999 Mar 15; 93(6): 2067-2074.

26. Yang R, Muller C, Huynh V, Fung YK, Yee AS, Koeffler HP. Functions of cyclin A1 in the cell cycle and its interactions with transcription factor E2F-1 and the Rb family of proteins. Molecular and cellular biology 1999 Mar; 19(3): 2400-2407.

27. Nakamaki T, Hamano Y, Hisatake J, Yokoyama A, Kawakami K, Tomoyasu S, et al. Elevated levels of cyclin A1 and A (A2) mRNA in acute myeloid leukaemia are associated with increased survival. Br J Haemato/ 2003 Oct; 123(1): 72-80.

28. Schwartz GK, Shah MA. Targeting the cell cycle: a new approach to cancer therapy. J Clin Oncol 2005 Dec 20; 23(36): 9408-9421.

29. Saito Y, Uchida N, Tanaka S, Suzuki N, Tomizawa-Murasawa M, Sone A, et al. Induction of cell cycle entry eliminates human leukemia stem cells in a mouse model of AML. Nat Biotechno/ 2010 Mar; 28(3): 275-280.

30. Prenzel T, Begus-Nahrmann Y, Kramer F, Hennion M, Hsu C, Gorsler T, et al. Estrogen-dependent gene transcription in human breast cancer cells relies upon proteasome-dependent monoubiquitination of 
histone H2B. Cancer research 2011 Sep 1; 71(17): 5739-5753.

31. Rao RC, Dou Y. Hijacked in cancer: the KMT2 (MLL) family of methyltransferases. Nature reviews Cancer 2015 Jun; 15(6): 334-346.

32. Wu L, Lee SY, Zhou B, Nguyen UT, Muir TW, Tan S, et al. ASH2L regulates ubiquitylation signaling to MLL: trans-regulation of H3 K4 methylation in higher eukaryotes. Molecular cel/ 2013 Mar 28; 49(6): 1108-1120.

33. Lee JS, Shukla A, Schneider J, Swanson SK, Washburn MP, Florens L, et al. Histone crosstalk between H2B monoubiquitination and H3 methylation mediated by COMPASS. Cel/ 2007 Dec 14; 131(6): 1084-1096.

34. Drexler HG, Quentmeier H, Macleod RA. Malignant hematopoietic cell lines: in vitro models for the study of MLL gene alterations. Leukemia 2004; 18(2): 227-232.

35. Qiao Z, Zhang Y, Ge M, Liu S, Jiang X, Shang Z, et al. Cancer Cell Derived Small Extracellular Vesicles Contribute to Recipient Cell Metastasis Through Promoting HGF/c-Met Pathway. Mol Cell Proteomics 2019 Aug; 18(8): 1619-1629.

36. Ge M, Luo Z, Qiao Z, Zhou Y, Cheng X, Geng Q, et al. HERP Binds TBK1 To Activate Innate Immunity and Repress Virus Replication in Response to Endoplasmic Reticulum Stress. J Immunol 2017 Nov 1; 199(9): 3280-3292.

37. Weinmann AS, Farnham PJ. Identification of unknown target genes of human transcription factors using chromatin immunoprecipitation. Methods 2002 Jan; 26(1): 37-47.

38. Wang S, Ge M, Cui J, Qiao Z, Chen X, Wu S, et al. Diminished interaction between mutant NOTCH1 and the NuRD corepressor complex upregulates CCL17 in chronic lymphocytic leukemia. Leukemia 2019 Dec; 33(12): 2951-2956.

39. Ge M, Qiao Z, Kong Y, Liang H, Sun Y, Lu H, et al. Modulating proteasome inhibitor tolerance in multiple myeloma: an alternative strategy to reverse inevitable resistance. Br J Cancer 2020 Nov 30.

40. Muller C, Yang R, Idos G, Tidow N, Diederichs S, Koch OM, et al. c-myb transactivates the human cyclin A1 promoter and induces cyclin A1 gene expression. Blood 1999 Dec 15; 94(12): 4255-4262.

41. Coisy M, Roure V, Ribot M, Philips A, Muchardt C, Blanchard JM, et al. Cyclin A repression in quiescent cells is associated with chromatin remodeling of its promoter and requires Brahma/SNF2alpha. Molecular cell 2004 Jul 2; 15(1): 43-56.

42. Liau BB, Sievers C, Donohue LK, Gillespie SM, Flavahan WA, Miller TE, et al. Adaptive Chromatin Remodeling Drives Glioblastoma Stem Cell Plasticity and Drug Tolerance. Cell stem cell 2017 Feb 2; 20(2): 233-246 e237.

43. Seligson DB, Horvath S, Shi T, Yu H, Tze S, Grunstein M, et al. Global histone modification patterns predict risk of prostate cancer recurrence. Nature 2005 Jun 30; 435(7046): 1262-1266.

44. Beesley AH, Rampellini JL, Palmer ML, Heng JY, Samuels AL, Firth MJ, et al. Influence of wild-type MLL on glucocorticoid sensitivity and response to DNA-damage in pediatric acute lymphoblastic leukemia. Molecular cancer 2010 Oct 28; 9: 284. 
45. Chauhan D, Tian Z, Nicholson B, Kumar KG, Zhou B, Carrasco R, et al. A small molecule inhibitor of ubiquitin-specific protease-7 induces apoptosis in multiple myeloma cells and overcomes bortezomib resistance. Cancer Cell 2012 Sep 11; 22(3): 345-358.

46. Kapuria V, Peterson LF, Fang D, Bornmann WG, Talpaz M, Donato NJ. Deubiquitinase inhibition by small-molecule WP1130 triggers aggresome formation and tumor cell apoptosis. Cancer Res 2010 Nov 15; 70(22): 9265-9276.

47. Dokumcu K, Farahani RM. Evolution of Resistance in Cancer: A Cell Cycle Perspective. Front Oncol 2019; 9: 376.

48. Hirama T, Koeffler HP. Role of the cyclin-dependent kinase inhibitors in the development of cancer. Blood 1995 Aug 1; 86(3): 841-854.

49. Kamb A, Gruis NA, Weaver-Feldhaus J, Liu Q, Harshman K, Tavtigian SV, et al. A cell cycle regulator potentially involved in genesis of many tumor types. Science 1994 Apr 15; 264(5157): 436-440.

50. Recasens A, Munoz L. Targeting Cancer Cell Dormancy. Trends Pharmacol Sci 2019 Feb; 40(2): 128141.

51. Garcia-Prat L, Martinez-Vicente M, Perdiguero E, Ortet L, Rodriguez-Ubreva J, Rebollo E, et al. Autophagy maintains stemness by preventing senescence. Nature 2016 Jan 7; 529(7584): 37-42.

52. Calame KL, Lin KI, Tunyaplin C. Regulatory mechanisms that determine the development and function of plasma cells. Annual review of immunology 2003; 21: 205-230.

53. Leung-Hagesteijn C, Erdmann N, Cheung G, Keats JJ, Stewart AK, Reece DE, et al. Xbp1s-negative tumor B cells and pre-plasmablasts mediate therapeutic proteasome inhibitor resistance in multiple myeloma. Cancer Cell 2013 Sep 9; 24(3): 289-304.

54. Zhang XD, Baladandayuthapani V, Lin H, Mulligan G, Li B, Esseltine DW, et al. Tight Junction Protein 1 Modulates Proteasome Capacity and Proteasome Inhibitor Sensitivity in Multiple Myeloma via EGFR/JAK1/STAT3 Signaling. Cancer Cell 2016 May 9; 29(5): 639-652.

55. Holm C, Ora I, Brunhoff C, Anagnostaki L, Landberg G, Persson JL. Cyclin A1 expression and associations with disease characteristics in childhood acute lymphoblastic leukemia. Leuk Res 2006 Mar; 30(3): 254-261.

56. Vaz M, Hwang SY, Kagiampakis I, Phallen J, Patil A, O'Hagan HM, et al. Chronic Cigarette SmokeInduced Epigenomic Changes Precede Sensitization of Bronchial Epithelial Cells to Single-Step Transformation by KRAS Mutations. Cancer Cell 2017 Sep 11; 32(3): 360-376 e366.

57. Flavahan WA, Gaskell E, Bernstein BE. Epigenetic plasticity and the hallmarks of cancer. Science 2017 Jul 21; 357(6348).

\section{Figures}


Figure 1

a

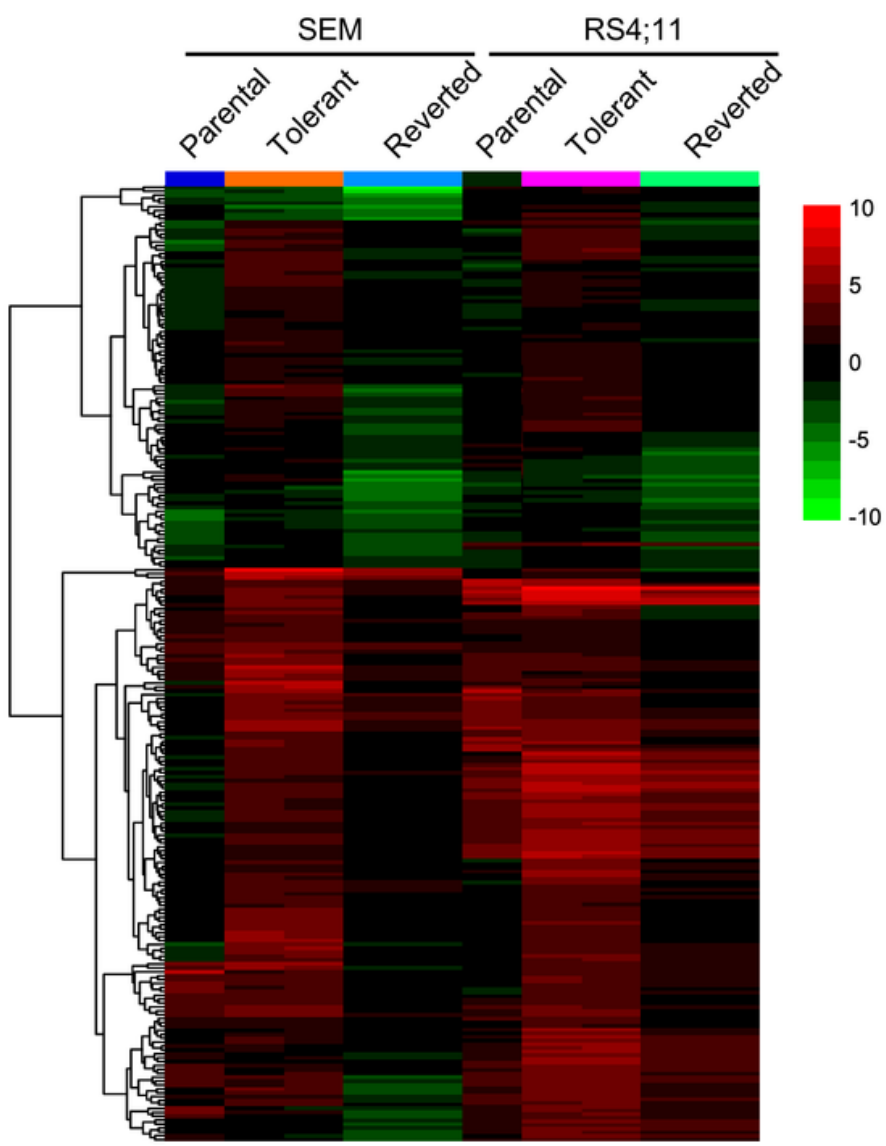

d

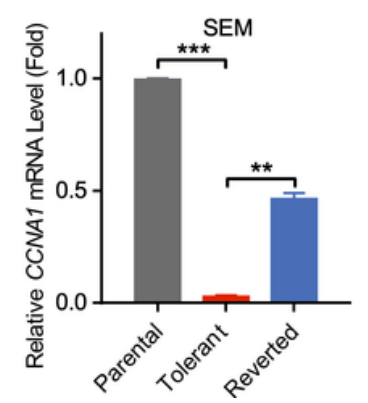

b
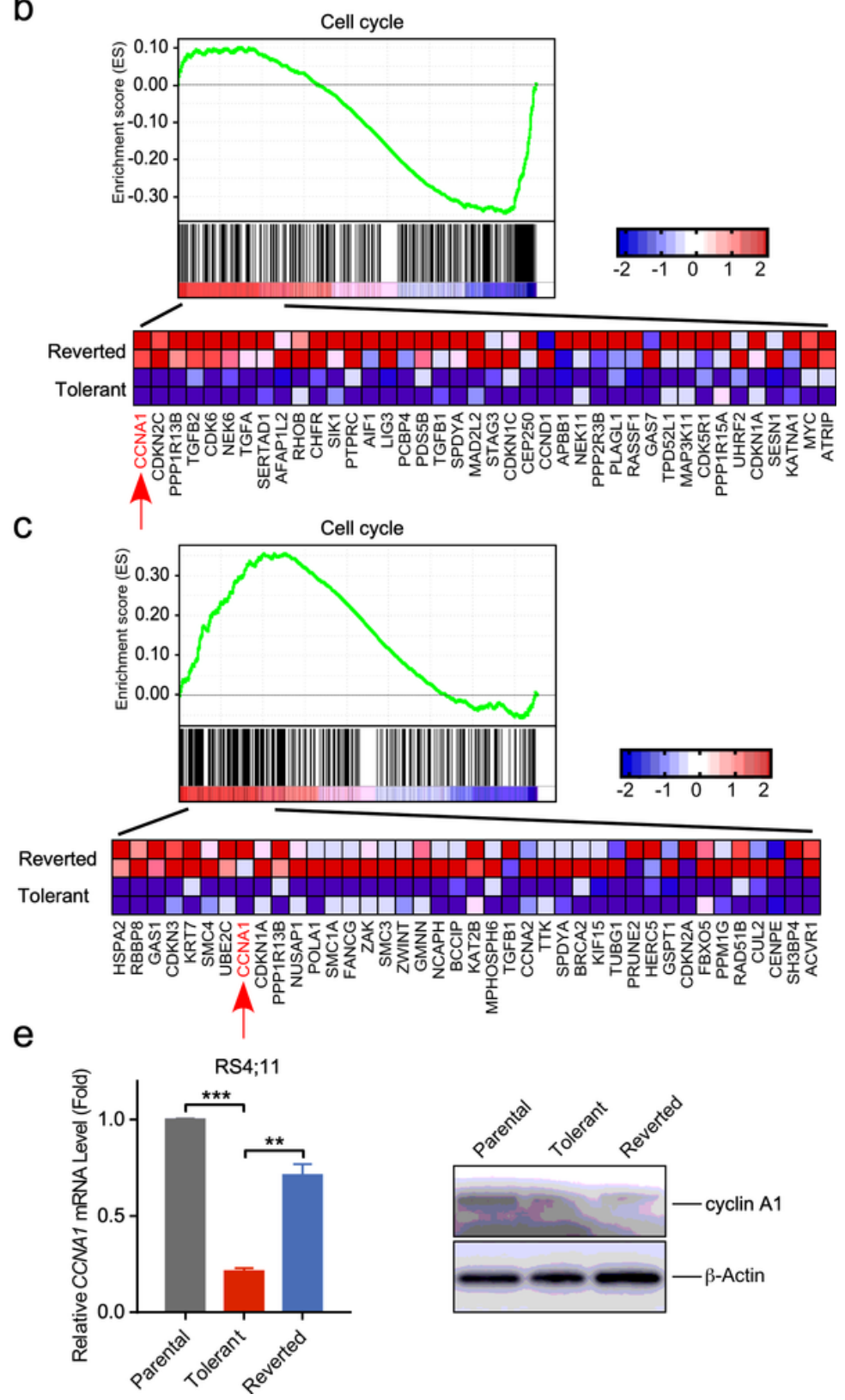

Figure 1

Cyclin A1 is downregulated in drug-tolerant MLL cells. (a) Unsupervised hierarchical clustering heatmap of differentially expressed genes (DEGs) in parental, tolerant, and reverted SEM and RS4;11 cells. (b, c) GSEA analysis of datasets obtained from the indicated SEM (b) and RS4;11 (c) cells. Heatmap showing the 40 most downregulated genes. (d, e) CCNA1 mRNA and cyclin A1 protein levels in the indicated cells. Relative mRNA expression values were normalized against GAPDH. $\beta$-Actin was used as a loading control in immunoblots. ${ }^{\star \star} \mathrm{P}<0.01$; ${ }^{\star \star \star} \mathrm{P}<0.001$; two-tailed t-test. Data represent the means of triplicate reactions \pm SD. 
Figure 2

a

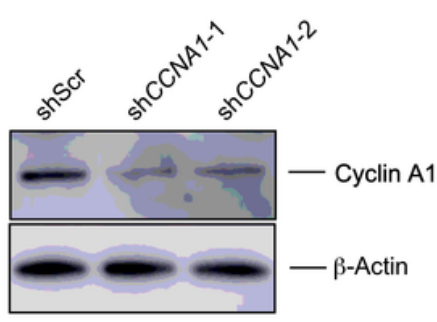

b

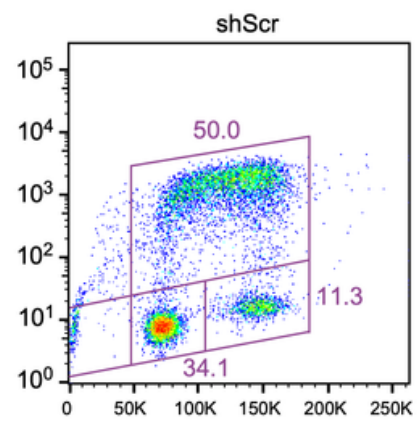

C

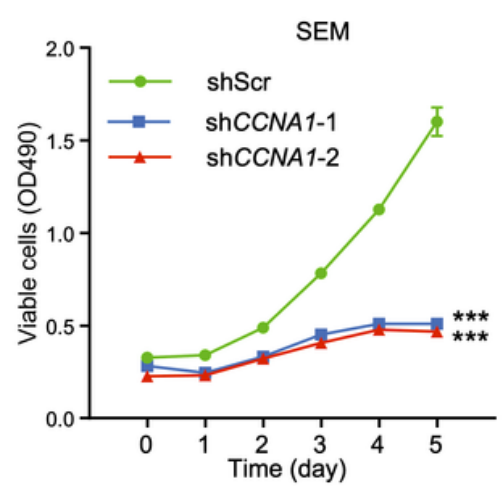

d

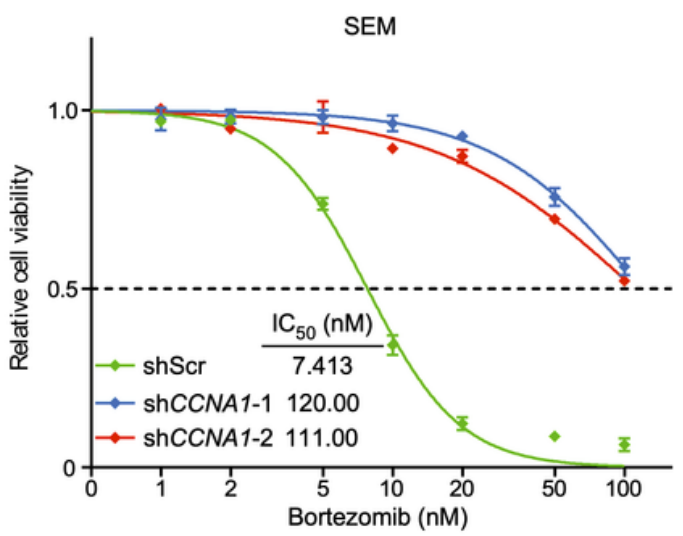

e

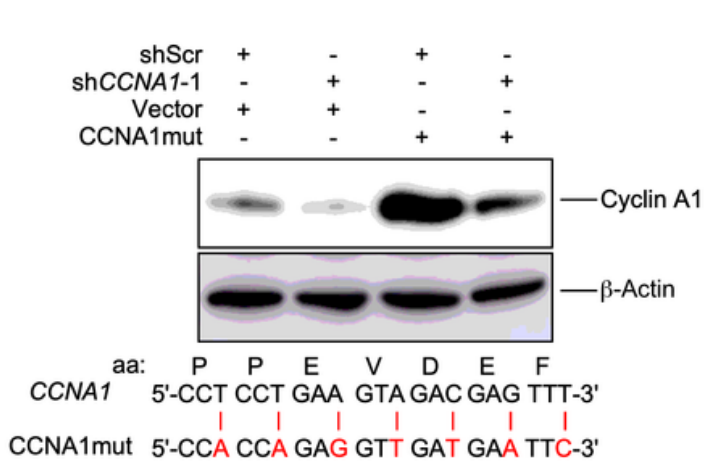

shCCNA1-1

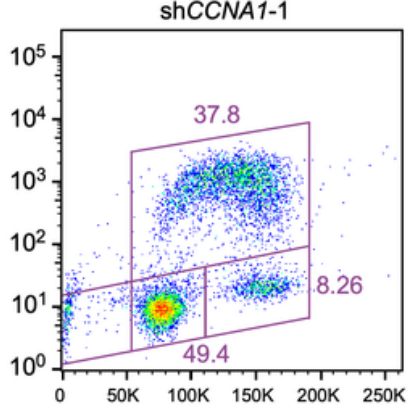

ShCCNA1-2

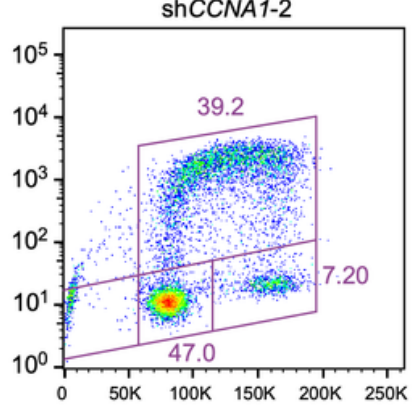

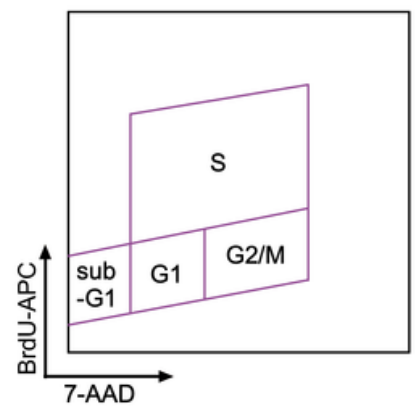

f

SEM

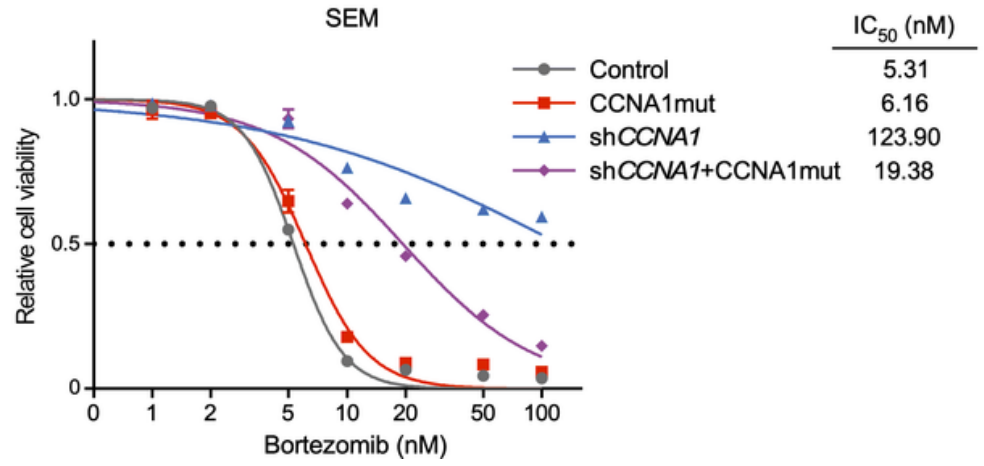

Figure 2

Cyclin A1 suppression induces drug tolerance in MLL cells. (a) SEM cells were infected with the indicated lentiviral vectors. Immunoblots of cyclin A1 in shScr and CCNA1-knockdown SEM cells were analyzed. (b) Cell cycle profiling of the indicated SEM cells. One representative of three independent experiments is shown. (c) Proliferation of SEM cells infected with indicated lentiviral vectors for 5 days. (d) Cell viability of indicated SEM cells. The IC50 of different cells was quantified. (e, f) SEM cells were infected with the indicated lentiviral vectors. Immunoblots (e) and cell viability (f) of the indicated cells were analyzed. CCNA1mut was based on the shCCNA1-1 sequence, which changed the base sequence without changing the amino acid sequence. ${ }^{\star \star \star} \mathrm{P}<0.001$; two-tailed t-test. Data represent the means of triplicate reactions \pm SD. 
Figure 3

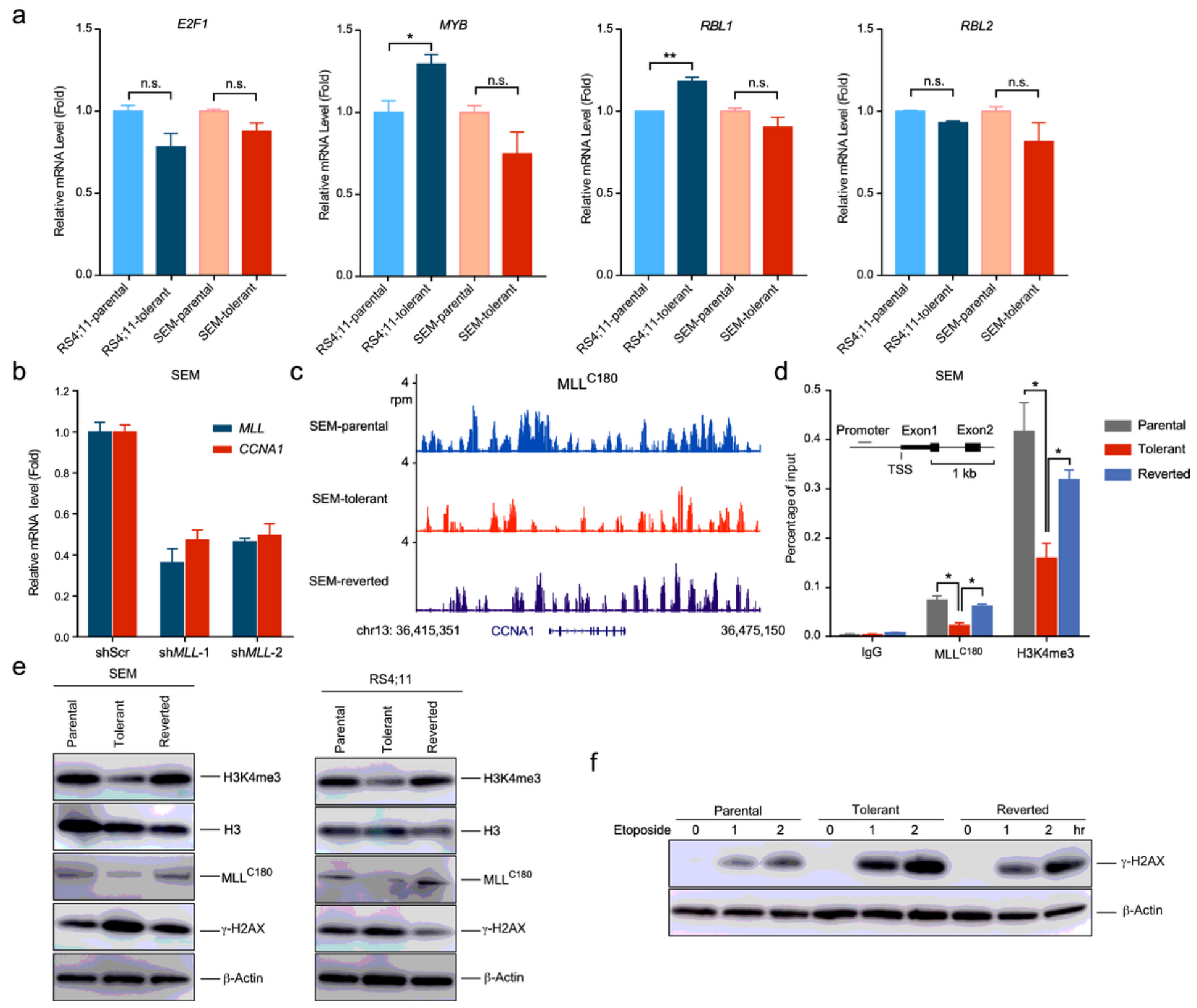

Figure 3

MLL directly regulates the transcriptional activity of cyclin A1. (a) Barplots showing expression levels of E2F1, MYB, RBL1, and RBL2 in parental and tolerant SEM and RS4;11 cells. (b) Genome browser tracks of MLLC180 ChIP-seq at CCNA1 loci in parental, tolerant, and reverted SEM cells. (c) ChIP analyses at the promoter region of the CCNA1 locus in the indicated SEM cells. TSS, transcription start site. (d) mRNA levels of SEM cells infected with the indicated lentiviral vectors. $(e, f)$ Immunoblots of endogenous wildtype MLL (MLLC180), histone, and histone modifications in the indicated cells. (g) Indicated SEM cells were treated with etoposide $(25 \mu \mathrm{M})$ and then analyzed by anti-yH2AX immunoblots. n.s., not significant; $\star P<0.05 ; * \star P<0.01$; two-tailed t-test. Data represent the means of triplicate reactions \pm SD. 
Figure 4

a

KMT2A

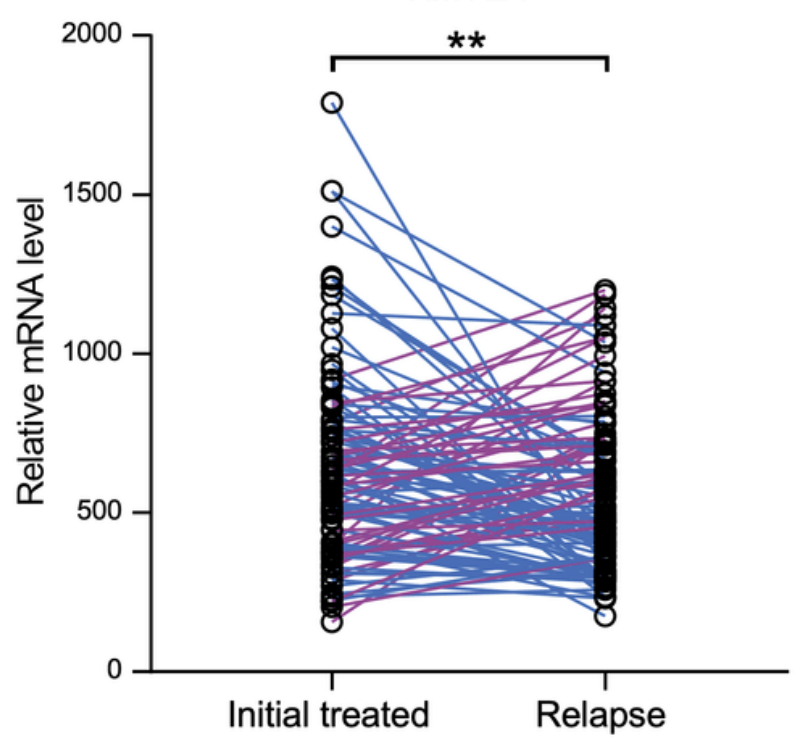

b

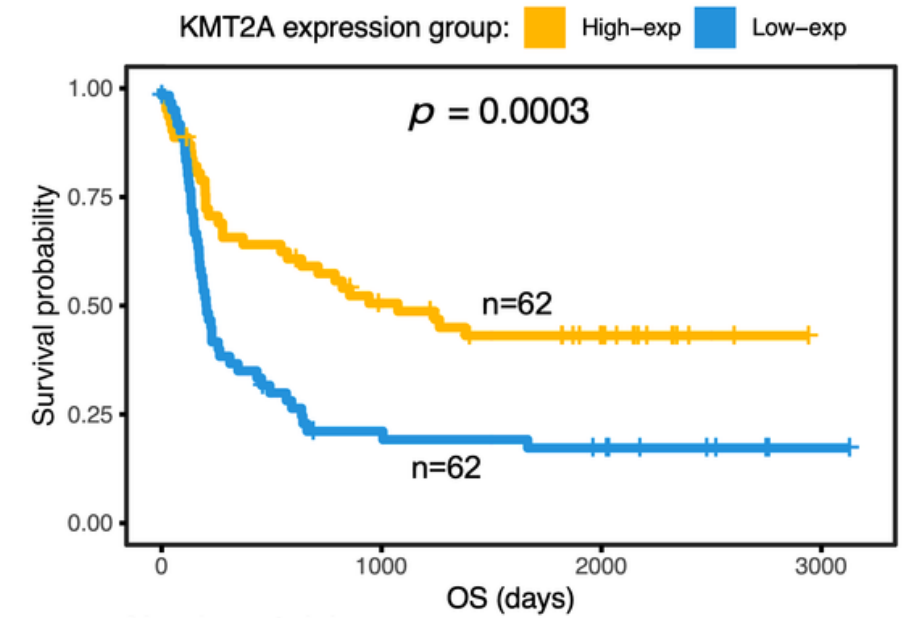

Number at risk

\begin{tabular}{l|llcl|} 
High-exp & 62 & 28 & 14 & 0 \\
Low-exp & 62 & 11 & 8 & 1 \\
\cline { 2 - 5 } & &
\end{tabular}
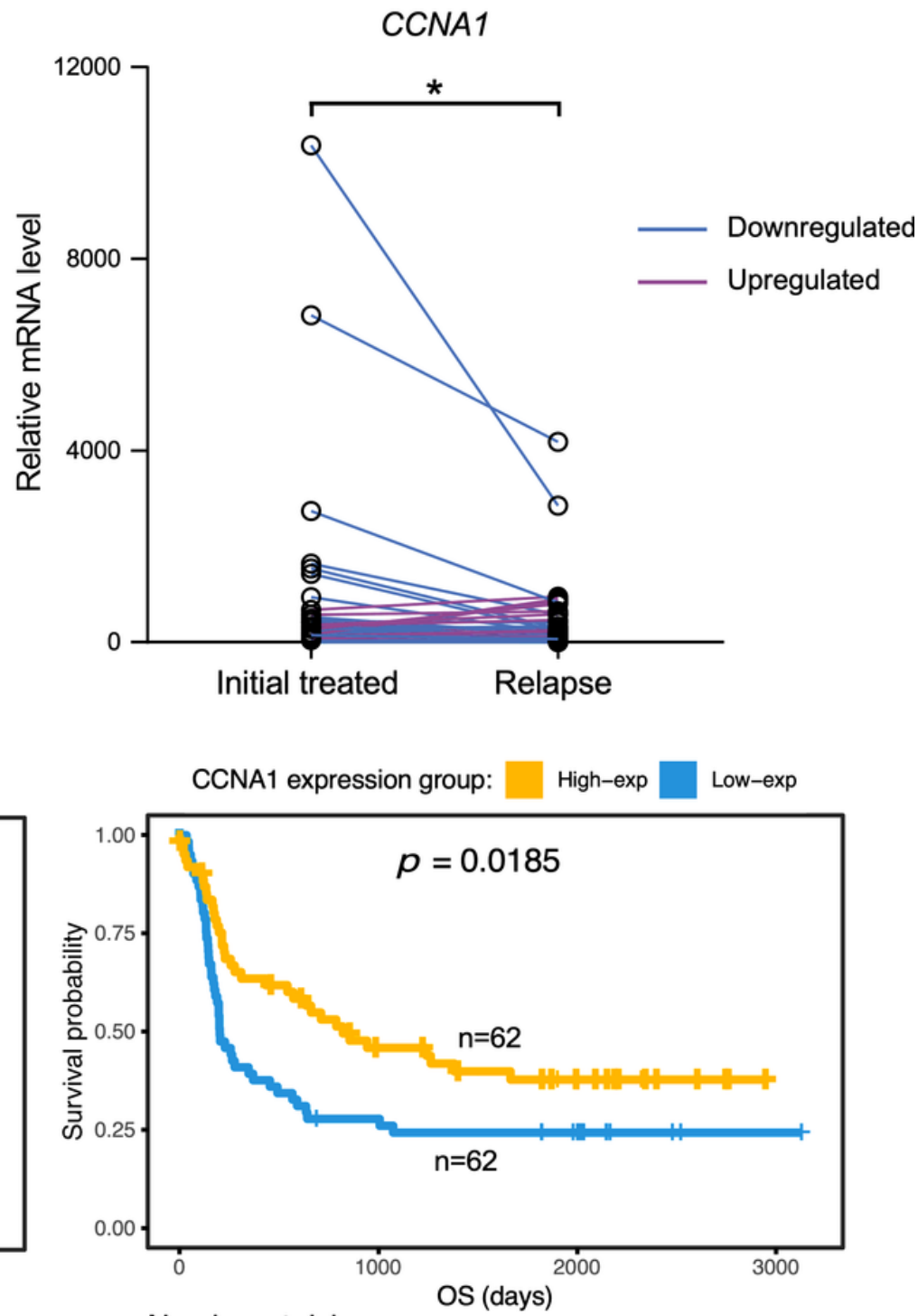

Number at risk

\begin{tabular}{l|llll|}
\cline { 2 - 4 } High-exp & 62 & 15 & 10 & 1 \\
Low-exp & 62 & 24 & 12 & 0 \\
\cline { 2 - 5 } & &
\end{tabular}

\section{Figure 4}

Downregulation of MLL and cyclin A1 is correlated with the short survival in ALL patients. (a) Line plots of mRNA levels in initial treated or relapsed ALL patients (pediatric ALL - Phase II, TARGET, 2018). Blue lines, downregulated genes; purple lines, upregulated genes. (b) Kaplan-Meier survival curve of ALL patients from the pediatric ALL - Phase II (TARGET, 2018) dataset (low expression: 50\%, $n=62$; high expression: $50 \%, n=62)$. ${ }^{*}<<0.05$; ${ }^{*} P<0.01$; by two-tailed t-test or log-rank test for significance. Data represent the means of triplicate reactions \pm SD. 
a

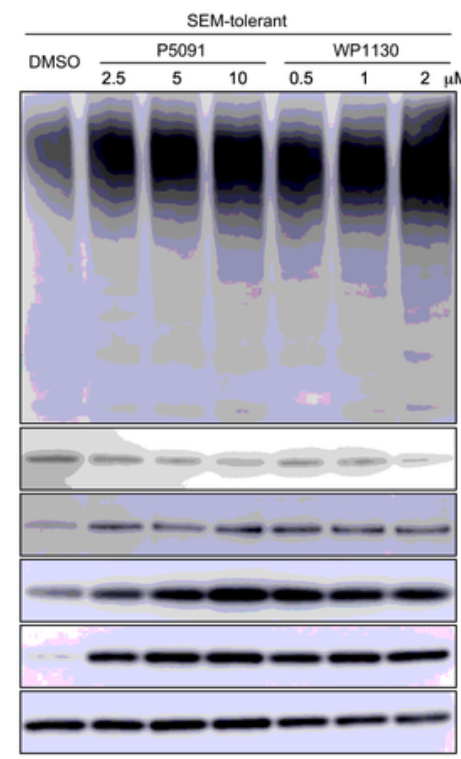

d

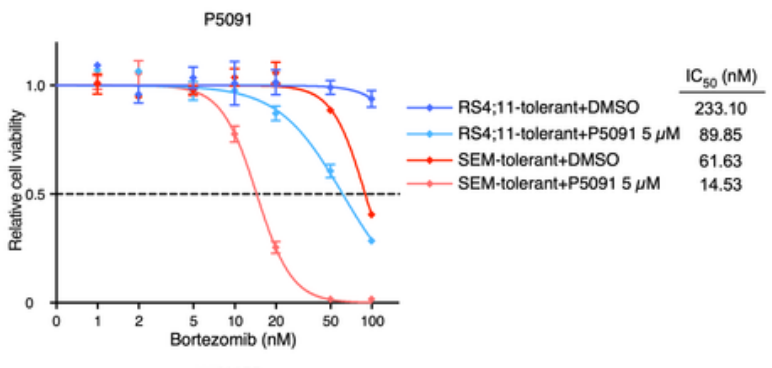

e

WP1130
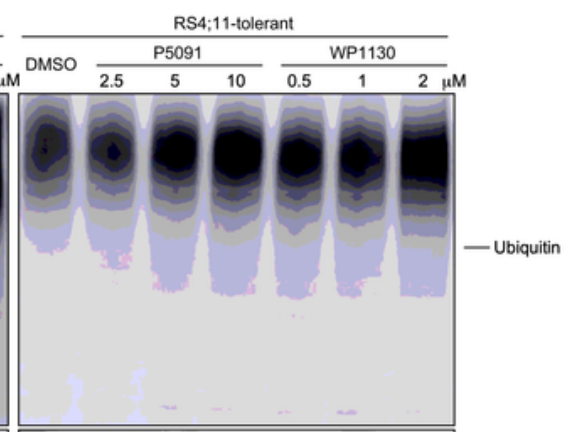

(

b
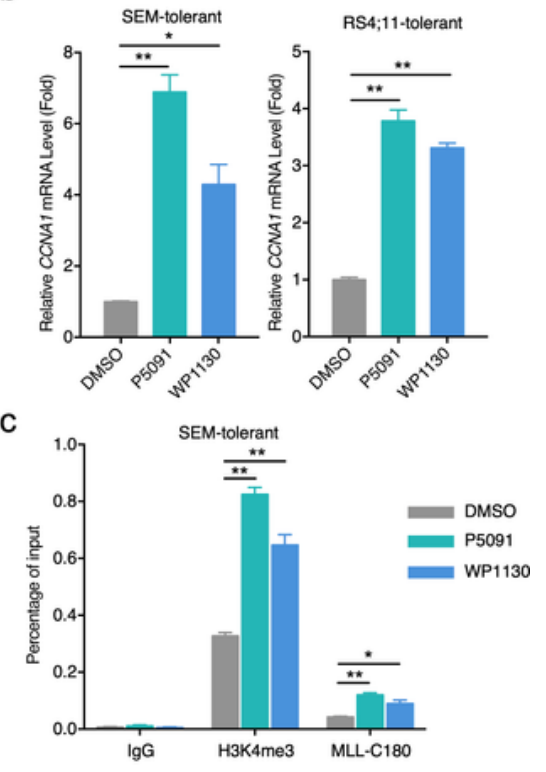

f

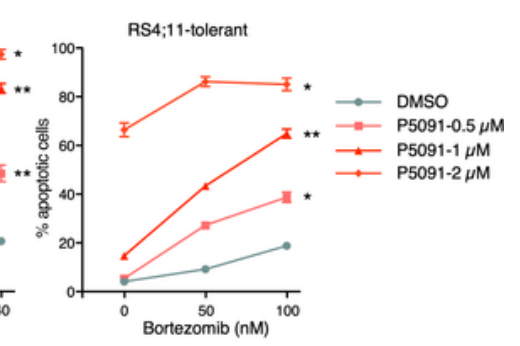

g

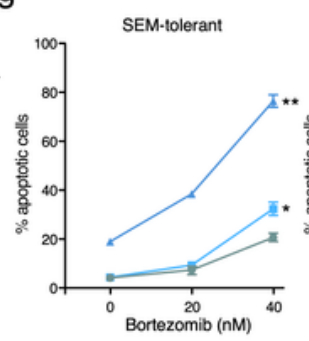

RS4;11-tolerant
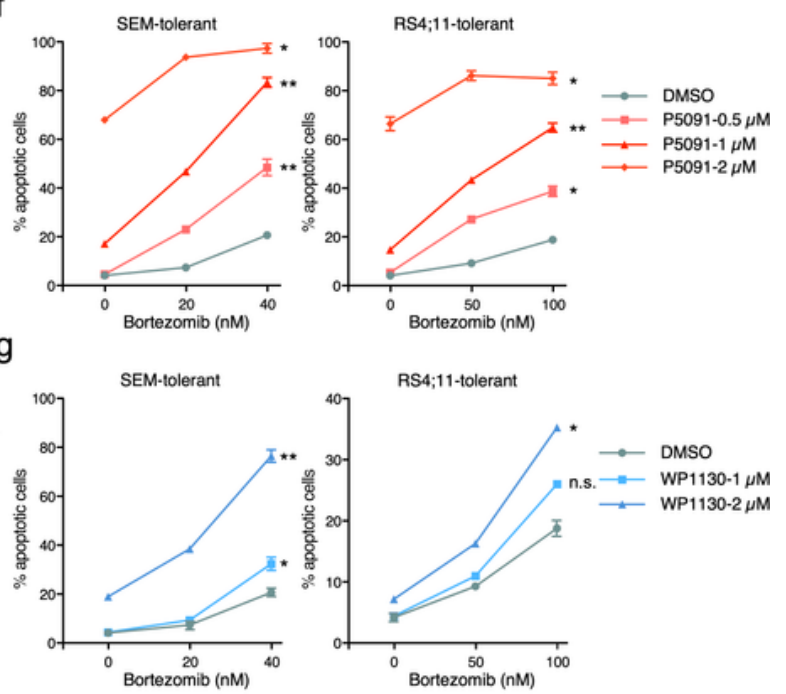

h

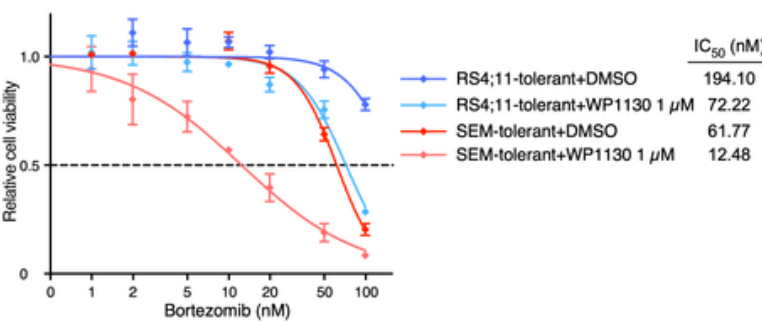

Parental cell

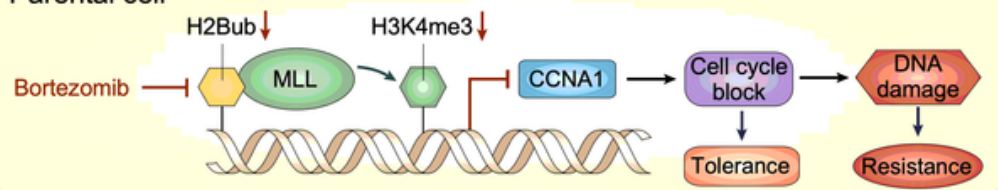

Tolerant cell

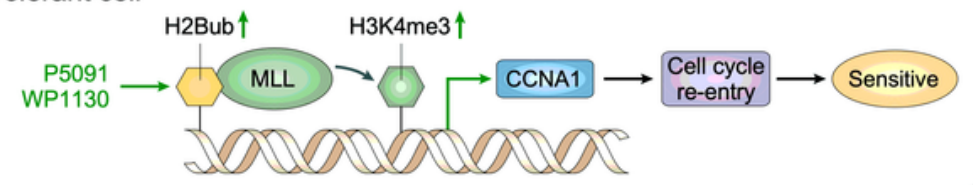

\section{Figure 5}

DUB inhibitors have potential efficacy against PI tolerance. (a, b) SEM and RS4;11 tolerant cells were treated with DMSO, P5091, or WP1130 for 20 hr. Immunoblots of the indicated antibodies (a) and CCNA1 mRNA levels (b) were analyzed. (c) ChIP analyses at the promoter region of the CCNA1 locus in SEM tolerant cells after the treatment with DMSO, P5091 $(5 \mu \mathrm{M})$, or WP1130 $(1 \mu \mathrm{M})$. Assays were performed with the indicated antibodies and immunoprecipitates were subjected to quantitative PCR analyses. (d, e) 
Cell viability of SEM and RS4;11 tolerant cells treated with $5 \mu \mathrm{M}$ P5091 (d) or $1 \mu \mathrm{M}$ WP1130 (e). (f, g) Apoptosis analysis of SEM and RS4;11 tolerant cells treated with the combination of bortezomib with

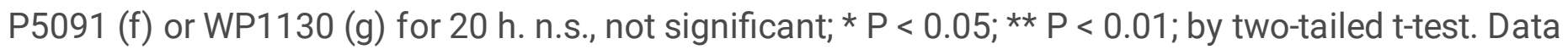
represent the means of triplicate reactions \pm SD. 